\title{
Bentall procedure after previous aortic valve or complete root replacement: Usefulness of self-assembled aortic valve conduit
}

\author{
Paul P. Urbanski, MD, PhD, Fitsum Lakew, MD, Witold Dinstak, MD, Nicolas Heinz, MD,
}

Michael Zacher, MD, Vadim Irimie, MD, and Wilko Reents, MD

\section{ABSTRACT}

Objectives: The aim of this study was to evaluate surgical results of complete aortic root replacement using self-assembled valve composite graft in the setting of destroyed aortic annulus after previous valve replacement.

Methods: Aortic root pathology being addressed by complete root replacement was combined with partial or complete absence of annular tissue in 112 consecutive patients. Eighty-eight had undergone a previous replacement of the aortic valve and 24 had undergone root replacement with a valved conduit. Altogether, 31 patients $(27.7 \%)$ presented with acute endocarditis, which was the indication for surgery in $75 \%$ of patients with prior root replacement. In all patients, the root replacement or re-replacement was performed with a self-assembled valved conduit using mechanical $(\mathrm{n}=74)$ or, in patients with an advanced age, biological $(\mathrm{n}=38)$ valve prostheses.

Results: In-hospital mortality was $11.6 \%$, including a 30 -day mortality of $6.3 \%$. Resternotomy for bleeding was necessary in $5.4 \%$ of patients and about onequarter did not need any blood transfusion. Estimated survival at 1, 5, and 10 years was $84.8 \% \pm 3.4 \%, 75.7 \% \pm 4.3 \%$, and $57.1 \% \pm 6.5 \%$, respectively. Freedom from any valve-related events at 10 years was $86.2 \% \pm 4.1 \%$. During the followup time (mean, $63 \pm 47$ months), there was only 1 reoperation necessary 9 years after surgery (replacement of deteriorated biological valve prosthesis within the vascular tube leaving the conduit untouched).

Conclusions: A self-assembled composite graft allows safe proximal fixation of the conduit in patients with destroyed aortic annulus, resulting in sufficient proximal anastomosis and a very low incidence of aorta-related reoperations. ( $\mathrm{J}$ Thorac Cardiovasc Surg 2018;156:89-95)

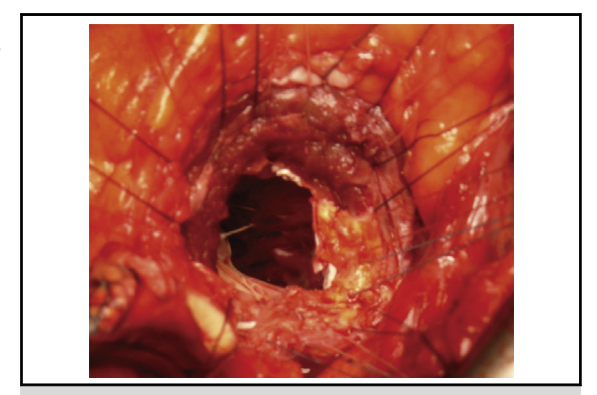

Lack of annular tissue after removal of infected conduit and extensive debridement.

\section{Central Message}

Self-assembled composite graft allows safe proximal fixation in patients who lack annular tissue.

\section{Perspective}

Placing a valve inside a conduit offers, in addition to many surgical and hemodynamic advantages, excellent hemostatic characteristics of the anastomosis performed between the fragile tissue and the collagen-sealed woven polyester tube and can be considered in several pathologic conditions, especially those that lack annular tissue.

See Editorial Commentary page 96.
The use of a valved conduit consisting of a mechanical or biological valve prosthesis and a vascular graft, as first described by Bentall and De Bono in 1968, ${ }^{1}$ has become a standard surgical technique for complete aortic root replacements. ${ }^{1-3}$ However, aortic root replacement in cases of aortic root pathology combined with a partial or

\footnotetext{
From the Cardiovascular Clinic Bad Neustadt, Bad Neustadt, Germany.

Received for publication July 26, 2017; revisions received Jan 4, 2018; accepted for publication Jan 30, 2018; available ahead of print March 30, 2018.

Address for reprints: Paul P. Urbanski, MD, PhD, Cardiovascular Clinic Bad Neustadt, Salzburger Leite 1, Bad Neustadt 97616, Germany (E-mail: p.urbanski@ kardiochirurg.de).

$0022-5223 / \$ 36.00$

Copyright (c) 2018 by The American Association for Thoracic Surgery

https://doi.org/10.1016/j.jtcvs.2018.01.105
}

complete lack of aortic annulus; for example, after extensive debridement in severe endocarditis or calcification of the annular tissue, especially after previous valve replacement, is among the most challenging conditions in cardiac surgery. ${ }^{4-6}$ In such situations, the use of a modified self-assembled composite graft, which combines the Cabrol and Kouchoukos techniques (the prosthesis is fixed inside the vascular tube

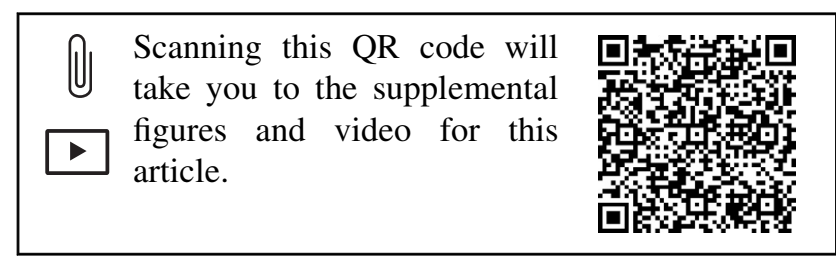




\section{Abbreviations and Acronyms}

$\mathrm{BVC}=$ biological valve conduit

$\mathrm{MVC}=$ mechanical valve conduit

leaving a flexible woven polyester rim for anastomosing to the left ventricular outflow tract and the coronary ostia implanted end to side to the conduit ${ }^{7}$ ) can be a very valuable option.

The aim of our study was to evaluate the operative and long-term results after applying this technique in patients with destroyed aortic annulus after previous aortic valve or complete root replacement with or without accompanying acute endocarditis, in whom anastomosing of the rigid valve prosthesis with the vulnerable tissue of the left ventricular outflow tract is especially problematic.

\section{PATIENTS AND METHODS}

From 2000 until 2014, a total of 560 patients underwent aortic root replacement in our institution. A self-assembled composite graft with a mechanical valve prosthesis $(n=371)$ or a biological valve prosthesis $(n=189)$ was used in all patients. Among them were 112 consecutive patients with several aortic root pathologies combined with partial or a complete lack of annular tissue (Figure 1) caused by extensive debridement of annular tissue after previous valve or complete root replacement. The root pathologies were accompanied by acute endocarditis in $27.7 \%$ of cases. All patients had had at least 1 preceding aortic valve operation, which was an aortic valve replacement in 88 patients $(78.6 \%)$ and a complete aortic root replacement with a valved conduit in 24 patients $(21.4 \%)$. Altogether, acute endocarditis of the artificial aortic valve was present in 31 patients $(27.7 \%)$, and in $75 \%$ of those who had undergone a previous Bentall procedure.

The complete root replacement was performed with a composite graft containing either a mechanical $(n=74[66.1 \%])$ or biological $(n=38$ $[33.9 \%]$ ) valve prosthesis. The choice of the valve prosthesis was predominantly determined by the patient's age (mean age of patients with mechanical valve conduit [MVC] and biological valve conduit [BVC] was $55 \pm 10$

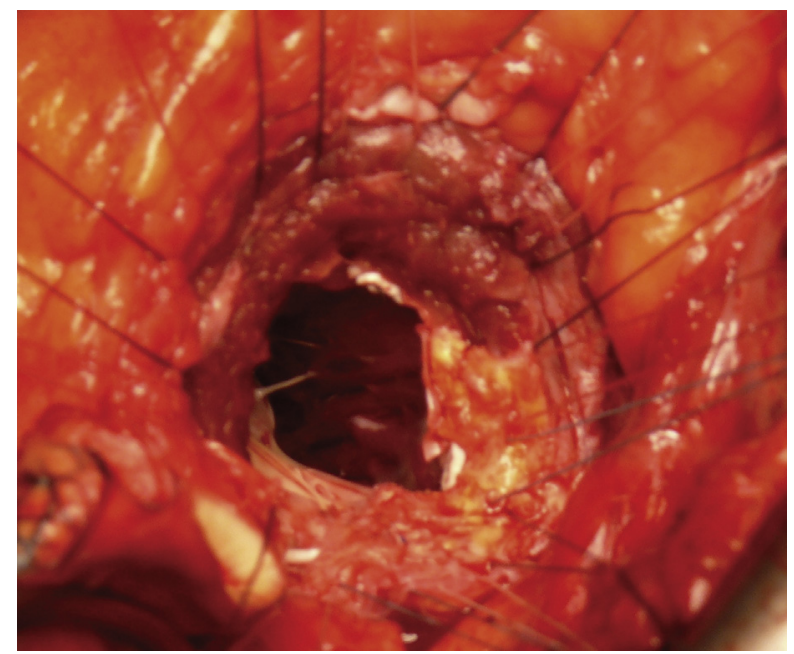

FIGURE 1. Intraoperative view of left ventricular outflow tract after removing of the infected artificial valved conduit and extensive debridement of aortic annular tissue. Pledgeted interrupted mattress sutures passed through bare ventricle muscle from inside to outside are visible. and $68 \pm 10$ years, respectively). The detailed preoperative patient characteristics are listed in Table 1.

\section{Surgical Technique}

Use of self-assembled mechanical or biological composite grafts has been established as the routine in our center for biological valves since 1998 and for mechanical valves since $2000{ }^{7,8}$ All patients underwent the operation via sternotomy. Arterial cannulation was performed through the ascending aorta whenever possible $(35.7 \%)$. In patients with a hostile aorta, arterial cannulation was performed through a common carotid $(44.6 \%)$ or a femoral artery $(19.7 \%)$. The entire artificial material (either the valve prosthesis or the entire conduit, as appropriate) was removed and extensive debridement of the affected annulus was performed, which led to a total or, at least partial, lack of annular tissue (Figure 1 and Video 1). Assembly of the composite grafts using mechanical and biological prostheses has been described previously. ${ }^{7-9}$ In brief, a conduit was assembled during surgery using a collagen-coated woven polyester vascular graft (InterGard; Maquet Cardiovascular, La Ciotat, France). The mechanical (St Jude Regent [St Jude Medical, St Paul, Minn] in 61 patients and Medtronic Aortic AP [Medtronic Inc, Minneapolis, Minn] in 13 patients) or biological prosthesis (Carpentier Edwards Perimount [Edwards Lifesciences, Irvine, Calif] in 20 patients, SPV Toronto [St Jude Medical] in 13 patients, and St Jude Trifecta [St Jude Medical] in 5 patients), was used in accordance with the patient's age. The valve prosthesis was placed inside the vascular prosthesis and attached approximately $5 \mathrm{~mm}$ above the proximal end of the tube with a continuous 4-0 polypropylene mattress suture (Figure 2 and Video 1). The length of the woven polyester skirt below

TABLE 1. Preoperative patient characteristics

\begin{tabular}{lc}
\hline \multicolumn{1}{c}{ Characteristic } & Result \\
\hline Age, y & $59 \pm 12(28-83)$ \\
Male sex & $85(75.9)$ \\
NYHA functional class III or IV & $50(44.6)$ \\
Concomitant disease & \\
Hypertension & $92(82.1)$ \\
Diabetes & $14(12.5)$ \\
COPD & $9(8.0)$ \\
Dialysis & $2(1.8)$ \\
Previous neurologic event & $19(17.0)$ \\
Permanent & $13(11.6)$ \\
Transient (no residuals) & $6(5.4)$ \\
Aortic root pathology & $112(100)$ \\
Aneurysm* & $73(65.2)$ \\
Conduit infection & $18(16.1)$ \\
Acute dissection & $5(4.5)$ \\
Others $\dagger$ & $16(14.3)$ \\
Acute endocarditis & $31(27.7)$ \\
Previous aortic valve/root surgery & $112(100)$ \\
Twice or more & $27(24.1)$ \\
Previous ascending & $30(26.8)$ \\
replacement & \\
Previous arch replacement & $4(3.6)$ \\
\hline EuroSCORE logistic $(\%)$ & $22.3(4.88-88.63)$ \\
\hline
\end{tabular}

Values are presented as $\mathrm{n}(\%)$ or mean \pm standard deviation (range). NYHA, New York Heart Association; COPD, chronic obstructive pulmonary disease; Euro$S C O R E$, European system for cardiac operative risk evaluation. *Including chronic dissection and false aneurysms. $\dagger$ Including porcelain aorta and/or procedure-related root injury. 


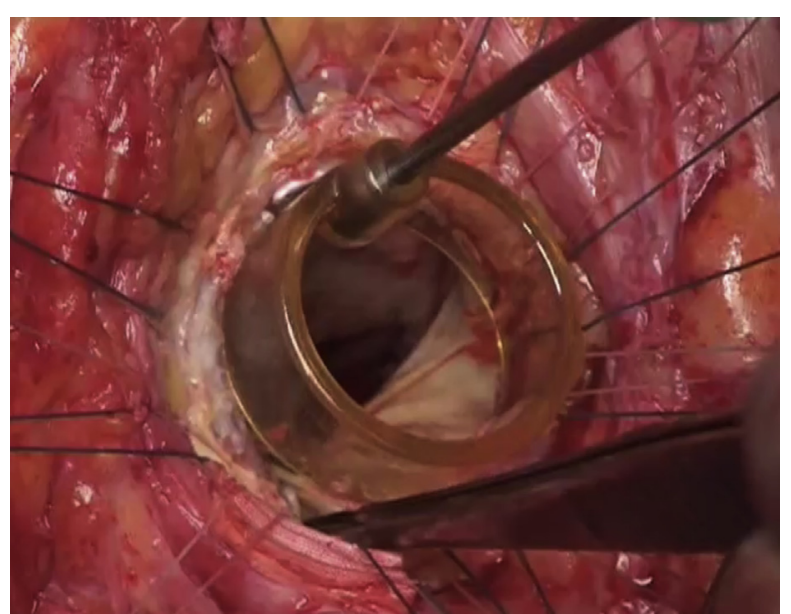

VIDEO 1. Removal of aortic composite graft (stentless valve prosthesis incorporated in a vascular tube) due to acute endocarditis 19 years after primary implantation. Extensive debridement of the aortic annulus is a prerequisite for the healing of a new prosthesis and frequently results in a lack of annular tissue (here, debridement took about $20 \%$ of the cardiac ischemia time). Pledgeted interrupted mattress sutures pass the remaining tissue from inside to outside. Self-assembling of the valved conduit using vascular woven polyester graft and any valve prosthesis (here biological stented valve prosthesis). The valve is fixed within the tube with running mattress polypropylene sutures, leaving approximately 5 to $10 \mathrm{~mm}$ free margin of graft below valve. (The length of the woven polyester skirt below the valve is determined according to surgical need.) The graft rim below the valve prosthesis is used to anastomose the composite graft to the left ventricular outflow tract with mattress sutures passing the woven polyester rim below the valve prosthesis from inside to outside. After removal of all artificial material and mobilization of the coronary ostia, the coronary arteries are reimplanted end to side with conduit. Distal anastomosis (here with arch prosthesis) completes the procedure. Video available at: http://www.jtcvsonline.org/article/S00225223(18)30716-5/fulltext.

the valve is determined according to surgical need; for example, the skirt can be completely or partially longer if more material is necessary for anastomosing with the left ventricular outflow tract (mostly at its mitral part). The upper margin of the stentless SPV Toronto valve prosthesis, which was used until the manufacturer took it off the market in 2008, was sutured to the tube with a second running suture. ${ }^{9}$ Because the valve prosthesis is placed above the annulus, an exact measurement of the annulus is not necessary, and in patients with a narrow anatomical annulus, considerable oversizing can be performed. $^{7-9}$ The conduit was then anastomosed to the annulus with interrupted pledgeted mattress sutures, passing them through the tissue of the left ventricular outflow tract from the ventricular side and through the rim of the tube graft rather than through the sewing cuff of the prosthetic valve (Figure 3 and Video 1). No additional steps were performed to reinforce the destructed annulus or left ventricular outflow tract. In patients with a complete absence of aortic annular tissue and concomitant mitral valve replacement ( 5 patients), the rim of the woven polyester tube was sewn to the suturing ring of a mitral valve prosthesis. The coronary ostia were excised from the aorta with small aortic wall buttons and, in most cases, mobilized and directly implanted to the conduit end to side, according to the Kouchoukos button technique. ${ }^{10}$ When the orifices of the coronary arteries were pathologically changed (calcified or destroyed by infection, which was especially frequent after previous aortic root replacement), the coronary arteries were implanted using a saphenous interposition graft or, in a few cases, even a coronary revascularization was performed after ligation of the ostia (Table 2). However, as emphasized in

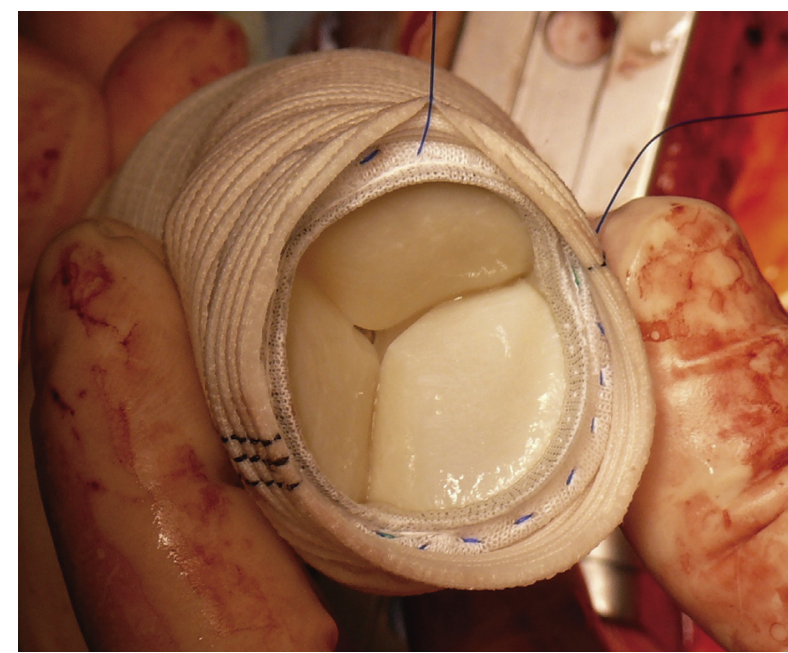

FIGURE 2. Self-assembling of valved conduit using vascular woven polyester graft and biological stented valve prosthesis. The valve is fixed within tube with running mattress polypropylene suture, leaving free margin of graft below the valve.

our previous reports, ${ }^{7-9,11,12}$ in no case was a direct reimplantation of the coronaries hindered by the supra-annular site of the valve within the tube. The surgical procedures and the operative data are shown in Table 2 .

\section{Statistical Analysis}

Informed consent was obtained for all patients, and all perioperative data were collected prospectively; however, institutional review board approval was waived for this study because of the retrospective and completely anonymous character of the analysis. The data analysis was performed according to reporting guidelines. ${ }^{13}$ Early mortality was considered for the postoperative time of 30 days as well as for the in-hospital stay. The patients were followed-up with echocardiography performed in our outpatient clinic or by their cardiologist, from whom the written documents and echocardiographic images were requested and reviewed. Categorical variables are expressed as frequency (\%) and continuous variables as mean \pm standard deviation. Continuous variables are expressed as mean \pm standard deviation. Additionally, single predictor logistic regression models were built using all independent variables available to identify risk factors of in-hospital mortality. Actuarial survival and freedom from valve-related events were estimated by the Kaplan-Meier method. The statistical analysis was performed with IBM-SPSS software (version 24.0; IBM-SPSS Inc, Armonk, NY).

\section{RESULTS}

\section{Operative and Hemodynamic Data}

The average diameter of patients' aortic annulus was $24.9 \pm 3.8 \mathrm{~mm}$ for which an average aortic valve prosthesis size of $25.9 \pm 2.8 \mathrm{~mm}$ was used. A mean gradient across the aortic valve prostheses in the postoperative echocardiographic examination was $9.1 \pm 3.7 \mathrm{~mm} \mathrm{Hg}(8.6 \pm 4.4$ in MVC patients and $9.7 \pm 3.3$ in BVC patients). The operative data are provided in detail in Table 2.

\section{Early Mortality and Morbidity}

There were 7 early deaths $(6.3 \%)$ during the 30 -day postoperative period. Five patients had had acute prosthetic 


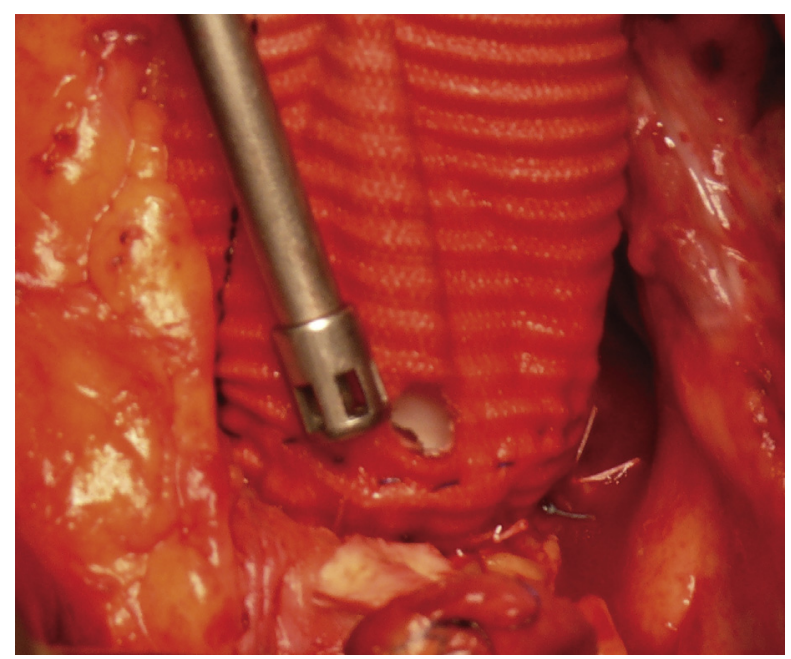

FIGURE 3. A hole for direct implantation of a coronary button is visible just above the continuous mattress suture fixating the sewing ring of the valve prosthesis with the woven polyester tube.

endocarditis and died because of its sequelae. One further patient, who underwent operation because of acute dissection with dissection-related occlusion of the right coronary artery, died due to right ventricular failure caused by myocardial infarction, despite a concomitant revascularization. The remaining patient experienced a rupture of the pulmonary artery shortly before closure of the chest and died because of uncontrolled bleeding before a cardiopulmonary bypass could be resumed.

All 7 patients mentioned above died before regaining consciousness, yet no new permanent postoperative

TABLE 2. Operative data

\begin{tabular}{lc}
\hline \multicolumn{1}{c}{ Variable } & Result \\
\hline CPB time, min & $199 \pm 58$ \\
\hline Aortic crossclamp time, min & $131 \pm 34$ \\
\hline Lowest rectal temperature, ${ }^{\circ} \mathrm{C}$ & $29 \pm 3.4$ \\
Circulatory arrest time, min $^{\prime}$ & $18 \pm 13$ \\
\hline Surgery time, min & $350 \pm 90$ \\
\hline Arch replacement & $11(9.8)$ \\
$\quad$ Total/subtotal & $5(4.5)$ \\
\hline Hemiarch replacement & $39(34.9)$ \\
CABG for CHD & $11(9.8)$ \\
\hline CAIG or CABG for ostial pathology & $15(13.4)$ \\
Myectomy & $5(4.5)$ \\
Mitral valve reconstruction & $2(1.8)$ \\
\hline Mitral valve replacement & $7(6.3)$ \\
\hline Tricuspid valve reconstruction & $2(1.8)$ \\
\hline
\end{tabular}

Values are presented as mean \pm standard deviation or $\mathrm{n}(\%) . C P B$, Cardiopulmonary bypass; $C A B G$, coronary artery bypass grafting; $C H D$, coronary heart disease; $C A I G$, coronary artery interposition graft. neurologic deficits were noted among the remaining patients. Transient neurologic dysfunction such as confusion, delirium, or agitation lasting more than 48 hours but without focal deficit was documented in 16 patients $(14.3 \%)$ (Table 3).

Resternotomy due to bleeding was necessary in only 6 patients $(5.4 \%)$, although no tissue glue was used in any patient. No bleeding was related to the proximal anastomosis of the conduit. In 27 patients ( $24.1 \%$ ), no blood transfusion was performed during the entire perioperative period.

\section{Survival}

Follow-up data was complete for all patients. The mean follow-up time for all patients was $63 \pm 47$ months (72 \pm 43 months for survivors).

There were a further 30 deaths reported beyond the 30-day postoperative period, including 6 deaths that occurred in the hospital. Five of the latter were caused by chronic-progressive multiorgan failure related to the primary valve endocarditis and sepsis, and 1 patient died because of congestive heart failure caused primarily by alcohol-toxic cardiomyopathy. The causes of the remaining late deaths are listed in Table 3.

Altogether, 10 of 13 in-hospital deaths were caused by the primary septic shock but in no case were signs of remaining or recurrent endocarditis found at autopsy. In the multivariable analysis, single-predictor logistic regression models were built using all independent variables available. Because of low number of occurrences, most models turned out to have limited applicability; however, it has to be emphasized that the endocarditis was the only variable that occurred in all models. Eventually, a model, adjusting the in-hospital mortality with endocarditis (odds ratio, 7.774; 95\% CI, 2.014-30.013; $P=.003$ ), logistic European system for cardiac operative risk evaluation score (containing other variables), coronary heart disease, and previous coronary artery bypass grafting revealed good accuracy in the receiver operating characteristic curve (with area under curve of 0.804) and in the goodness-of-fit test (HosmerLemshow) test.

The actuarial survival at 1,5 , and 10 years was $84.8 \% \pm 3.4 \%, 75.7 \% \pm 4.3 \%$, and $57.1 \% \pm 6.5 \%$, respectively (Figure 4). The actuarial survivals in specific pathology (endocarditis vs nonendocarditis) are demonstrated in Figure E1, whereas the survivals in MVC and $\mathrm{BVC}$ patients, which reflect a considerable age difference $(55 \pm 10$ vs $68 \pm 10$ years), are shown in Figure E2.

\section{Reoperation}

No patient from the MVC cohort needed a reoperation on the aortic valve or the aortic root during the follow-up time. Among the BVC patients, 1 needed a reoperation 9 years after the composite graft operation because of structural valve deterioration. The patient received a valve re-replacement 
TABLE 3. Postoperative outcomes

\begin{tabular}{|c|c|}
\hline Variable & Result \\
\hline \multicolumn{2}{|l|}{ Early mortality } \\
\hline $30-d$ & $7(6.3)$ \\
\hline In-hospital* & 13 (11.6) \\
\hline Re-thoracotomy for bleeding & $6(5.4)$ \\
\hline \multicolumn{2}{|l|}{ Neurologic deficit $\dagger$} \\
\hline Permanent & 0 \\
\hline Transient (no residuals) & $2(3.6)$ \\
\hline Temporary dysfunction $\ddagger$ & $16(14.3)$ \\
\hline Dialysis & $11(9.8)$ \\
\hline Tracheostomy & $12(10.7)$ \\
\hline Late deaths $\S$ & $24(21.4)$ \\
\hline No valve and/or cardiac-related & $8(7.1)$ \\
\hline Unknown & $9(8.0)$ \\
\hline Cardiac & $7(6.3)$ \\
\hline \multicolumn{2}{|l|}{ Late valve-related events } \\
\hline Thromboembolism & $5(4.5)$ \\
\hline Bleeding & $5(4.5)$ \\
\hline Valve/root reoperation & $1(0.9)$ \\
\hline Endocarditis & 0 \\
\hline
\end{tabular}

within the vascular tube, leaving the conduit and the coronary ostia untouched.

\section{Structural and/or Nonstructural Valve Deterioration}

In no case was a paravalvular leak between the tube and the valve prosthesis observed. Structural valve deterioration requiring surgery was noted in only 1 patient, as reported above.

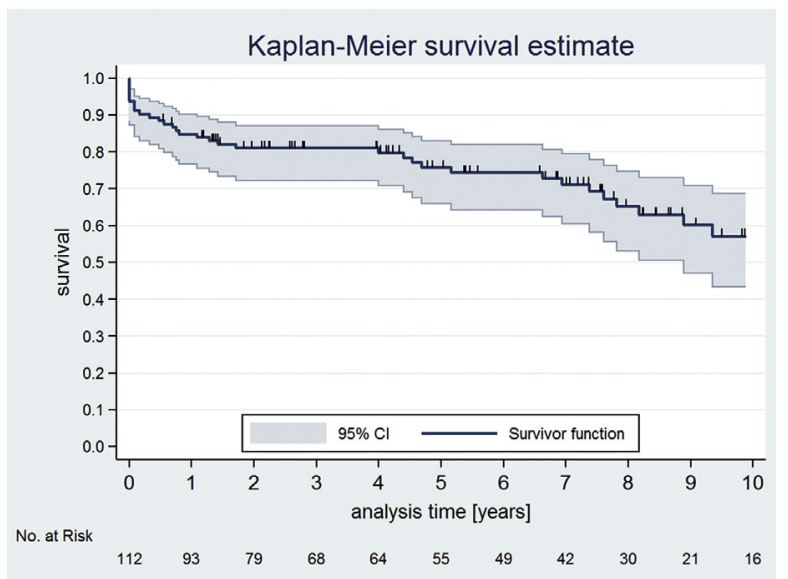

FIGURE 4. Actuarial survival (Kaplan-Meier) in patients with aortic root replacement after previous aortic valve replacement (with any grade of destroyed aortic annulus). CI, Confidence interval.

\section{Endocarditis}

New or recurrent endocarditis was not observed in any patient.

\section{Hemorrhagic and Thromboembolic Events}

Warfarin was given to all MVC patients and to $10 \mathrm{BVC}$ patients experiencing atrial fibrillation. Accordingly, there were 3 bleeding episodes in the MVC subcohort and 1 bleeding episode among the BVC patients receiving warfarin treatment. None of them was cerebral; however, there was 1 minor cerebral bleeding (without residuals) in $1 \mathrm{BVC}$ patient who was given aspirin. There were 3 thromboembolic events (strokes) in MVC patients and 2 strokes in BVC patients (Table 3). The 2 strokes in the BVC subcohort were diagnostically related to carotid stenosis or ulcerous atherosclerosis of the aortic arch, respectively.

Altogether, freedom from any valve- and/or root-related morbidity at 1,5 , and 10 years was $99.0 \% \pm 1.0 \%$, $88.0 \% \pm 3.8 \%$, and $86.2 \% \pm 4.1 \%$, respectively (Figure 5).

\section{DISCUSSION}

A complete aortic root replacement is nowadays a surgical standard, which, under normal circumstances, can be performed with a similar risk as an isolated aortic valve replacement, regardless of whether or not a mechanical or biological valve prosthesis is used. ${ }^{11,12}$ When patients with major pathologies such as aortic dissection and especially aortic root destruction and/or infection are excluded, operative mortality and major morbidity rates $<1 \%$ can be expected. ${ }^{2}$ Yet, the above-mentioned patients with destructive valve and root pathologies are exactly those who are at the highest risk and represent the exceptional surgical challenge. The latter is especially attributed to the lack of fibrous annulus, which is of utmost importance for a sufficient anastomosis between the tissue of the ventriculoaortic junction and the rigid sewing ring of the valve prosthesis. For this reason, some authors advocate using an aortic root homograft or xenograft because the biological material is pliable and offers much better tissue adaptation for the destroyed annulus. ${ }^{14,15}$ However, these grafts carry a significant risk of aortic wall calcification (Figure E3), which in the case of later occurring valve deterioration, frequently makes a complete root replacement necessary. Nevertheless, even if the use of biological valves is gaining increased interest, there are still many patients in whom a definite surgery-for example, by use of a mechanical valve-should be striven for, especially because the commonly used argument that biological material offers better resistance against bacterial infection has been disproved in many experimental and clinical applications. ${ }^{16-18}$ In our opinion, the debridement of all infected tissue is a prerequisite for the healing of the artificial 


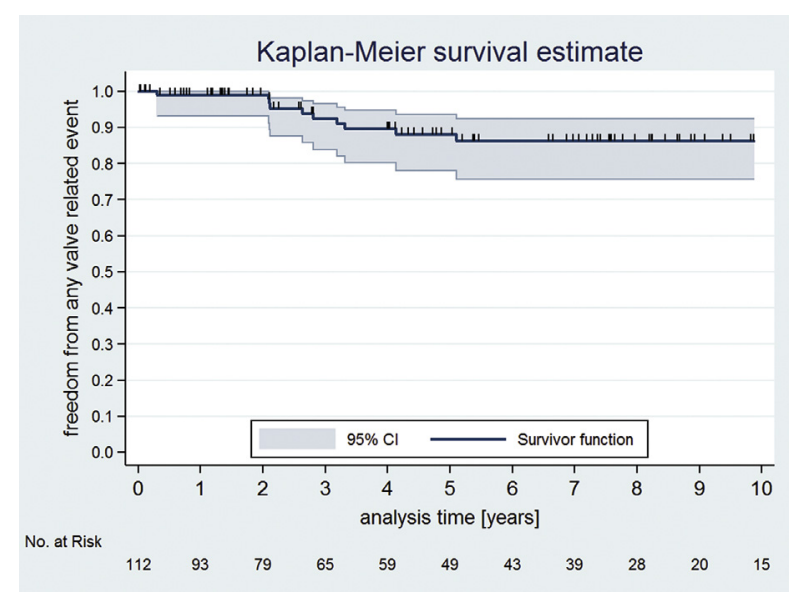

FIGURE 5. Freedom from any valve- and/or root-related events. $C I$, Confidence interval.

material, but on the other hand, the extensive debridement leads to a considerable lack of annular tissue. This can also occur after removing a previously implanted aortic valve and/or root prosthesis in nonendocarditis cases, especially if additional extensive decalcification is necessary. The subsequent lack of annular tissue is very hazardous for anastomosing the rigid sewing ring of a valve prosthesis (which is generally used for the proximal anastomosing in all commercially available and even in many self-assembled valve conduits) to the tearable tissue of the left ventricular outflow tract. All surgical solutions dealing with this problem have in common a tension-free anastomosing of the fragile tissue to a piece of pliable artificial or biological material and then suturing it to the sewing ring of a valved conduit. ${ }^{19-21}$ Placing the valve inside a self-assembled conduit aims for the same target yet makes the technique very simple and reproducible. For assembly of the aortic valve composite graft, any available mechanical or biological valve prosthesis and any vascular graft can be used according to the surgeon's preferences. Suturing the valve prosthesis within the tube takes only few minutes, resulting in irrelevantly prolonged ischemic times when they are compared with implantation times of commercially available valved conduits reported in the literature. ${ }^{2,3,11,12}$ Consequently, all surgeons can be taught the technique, which can easily help to overcome several challenging situations during aortic root replacement, and for this reason is used in our clinic by all attending surgeons exclusively. In addition to advantageous hemostatic characteristics of the anastomosis performed between the fragile tissue and the collagen-sealed woven polyester tube, the described method provides excellent hemodynamic features, especially in cases with a small aortic annulus because the valve prosthesis is placed above the annulus and can be oversized. ${ }^{22}$ Lastly, it enables a valve re-replacement within the conduit leaving the reimplanted coronary ostia untouched. In the described population, only 1 case of valve prosthesis replacement was presented, yet we have already been confronted with a total of 7 cases of valve deterioration during our entire 18-year-long experience. In all cases, aortic valve re-replacement was performed within the vascular tube leaving the root prosthesis and the implanted coronary ostia untouched. ${ }^{23}$

The lack of randomization and the retrospective character can be considered limitations of the study. Also the assessment of the annulus destruction grade is based on individual judgment of the operating surgeon and cannot be objectively standardized. Yet, in patients presenting fundamentally different pathologies and clinical conditions, any randomization of different surgical approaches, which are not equivalent alternatives, is hardly possible and can be burdened by selection bias. Moreover, the rarity of such complex aortic pathologies results in a small series with limited possibilities of reliable statistical evaluation. The latter is also true for our cohort; however, the examined cohort represents the entire clinic experience with aortic root replacement for which only 1 surgical method with self-assembled valve conduit was used.

\section{CONCLUSIONS}

The results presented here are in agreement with other reports demonstrating that survival in destructive pathologies of the aortic root is mainly determined by the infectious etiology, resulting in a high rate of in-hospital mortality., ${ }^{5,24}$ Nevertheless, it could also be demonstrated that the selfassembled composite graft was very useful for the Bentall procedure after previous aortic valve replacement and, despite any grade of annular destruction, offered a very sufficient and tight proximal anastomosis and very low incidence of aorta-related reoperations.

\section{Conflict of Interest Statement}

Dr Urbanski is a consultant for and has a financial relationship with Maquet Cardiovascular, Inc. All other authors have nothing to disclose with regard to commercial support.

The authors thank Melissa Lindner for providing assistance in preparing this article.

\section{References}

1. Bentall H, De Bono A. A technique for complete replacement of the ascending aorta. Thorax. 1968;23:338-9.

2. Gaudino M, Lau C, Munjal M, Avgerinos D, Girardi LN. Contemporary outcome of surgery for the aortic root aneurysms: a propensity-matched comparison of valve-sparing and composite valve graft replacement. J Thorac Cardiovasc Surg. 2015;150:1120-9.

3. Etz CD, Bischoff MS, Bodian C, Roder F, Brenner R, Griepp RB, et al. The Bentall procedure: is it the gold standard? A series of 597 consecutive cases. J Thorac Cardiovasc Surg. 2010;140(Suppl):S64-70.

4. El-Hamamsy I, Ibrahim M, Stevens LM, Witzke H, Clark L, Yacoub MH. Early and long term results of reoperative total aortic root replacement with reimplantation of the coronary arteries. J Thorac Cardiovasc Surg. 2011;142:1473-7. 
5. Jassar AS, Desai ND, Kobrin D, Pochettino A, Vallabhajosyula P, Milewski RK, et al. Outcome of aortic root replacement after previous aortic root replacement: the "true" redo root. Ann Thorac Surg. 2015;99:1601-9.

6. Garrido-Olivares L, Maganti M, Armstrong S, David TE. Clinical outcomes of aortic root replacement after previous aortic root replacement. J Thorac Cardiovasc Surg. 2013;146:611-5.

7. Urbanski PP, Diegeler A, Siebel A, Zacher M, Hacker RW. Valved stentless composite graft: clinical outcomes and hemodynamic characteristics. Ann Thorac Surg. 2003;75:467-71

8. Urbanski PP, Dinstak W, Frank S, Siebel A, Hacker RW. Modified versus standard mechanical valved aortic conduit. Asian Cardiovasc Thorac Ann. 2005; 13:53-7.

9. Urbanski PP, Heinz N, Zhan X, Hijazi H, Zacher M, Diegeler A. Modified bioBentall procedure: 10-year experience. Eur J Cardiothorac Surg. 2010;37: 1317-21.

10. Kouchoukos NT, Marshall WG Jr, Wedige-Stecher TA. Eleven-year experience with composite graft replacement of the ascending aorta and aortic valve. J Thorac Cardiovasc Surg. 1986;92:691-705.

11. Urbanski PP, Heinz N, Zacher M, Diegeler A. Bio-Bentall procedure versus isolated biological aortic valve replacement: a case-match study. Eur J Cardiothorac Surg. 2015;47:1077-82.

12. Urbanski PP, Wagner M, Zacher M, Hacker RW. Aortic root replacement versus aortic valve replacement: a case-match study. Ann Thorac Surg. 2001;72:28-32.

13. Akins CW, Miller DC, Turina MI, Kouchoukos NT, Blackstone EH, Grunkemeier GL, et al. Guidelines for reporting mortality and morbidity after cardiac valve interventions. Ann Thorac Surg. 2008;85:1490-5.

14. Niwaya K, Knott-Craig CJ, Santangelo K, Lane MM, Chandrasekaran K, Elkins RC. Advantage of autograft and homograft valve replacement for complex aortic valve endocarditis. Ann Thorac Surg. 1999;67:1603-8.

15. Okada K, Tanaka H, Takahashi H, Morimoto N, Munakata H, Asano M, et al. Aortic root replacement for destructive aortic valve endocarditis with left ventricular-aortic discontinuity. Ann Thorac Surg. 2008;85:940-5.
16. Rowe NM, Impellizzeri P, Vaynblat M, Lawson NM, Yoon DK, Sierra M, et al Studies in thoracic aortic graft infections: the development of a porcine mode and a comparison of collagen-impregnated Dacron grafts and cryopreserved allografts. J Thorac Cardiovasc Surg. 1999;118:857-65.

17. Leyh RG, Knobloch K, Hagl C, Ruhparwar A, Fischer S, Kofidis T, et al. Replacement of the aortic root for acute prosthetic valve endocarditis: prosthetic composite versus aortic allograft root replacement. J Thorac Cardiovasc Surg. 2004; $127: 1416-20$

18. Hagl C, Gall JD, Lansman SL, Fink D, Bodian CA, Spielvogel D, et al. Replacing the ascending aorta and aortic valve for acute prosthetic valve endocarditis: is using prosthetic material contraindicated? Ann Thorac Surg. 2002;74(Suppl): S1781-5.

19. Krasopoulos G, David TE, Armstrong S. Custom-tailored valved conduit for complex aortic root disease. J Thorac Cardiovasc Surg. 2008;135:3-7.

20. Nakamura Y, Tagusari O, Kobayashi J, Nakajima H. Secure anastomosis for damaged aortic root reconstruction: graft insertion technique. J Thorac Cardiovasc Surg. 2011;142:948-50.

21. Doi K, Ohira S, Dohi M, Yamamoto T, Okawa K, Yaku H. A novel technique of aortic root reconstruction for extensive endocarditis: the pericardial skirt technique. Ann Thorac Surg. 2014;98:1121-3.

22. Urbanski PP, Dinstak W, Rents W, Heinz N, Diegeler A. Long-term results after aortic root replacement using self-assembled valve composite grafts in patients with small aortic annulus. Interact Cardiovasc Thorac Surg. 2014; 18:159-63.

23. Urbanski PP. Replacement of valve prosthesis within aortic composite graft. Ann Thorac Surg. 2009;88:2024-5.

24. Shah DK, Li Z, Park SJ, Daly RC, Dearani JA, Schaff HV, et al. Replacement of the infected composite aortic root prosthesis. Ann Thorac Surg. 2011;92:1651-5.

Key Words: aortic root, aortic valve, composite graft, aortic redo surgery, endocarditis

Readers who found these articles interesting may also like to read the following papers found in recent and future issues of our sister publications, Seminars in Thoracic and Cardiovascular Surgery and Operative Techniques in Thoracic and Cardiovascular Surgery!

\section{Adult: Aortic Valve}

STATE OF THE ART: Aortic Valve Replacement: Are We Spoiled for Choice? Mohamad Bashir. Semin Thoracic Surg 2017: 265-272. ORIGINAL SUBMISSION: Single Dose Del Nido Cardioplegia in Minimally Invasive Aortic Valve Surgery. Daniel Ziazadeh. Semin Thoracic Surg 2017: 471-476.

Editorial Commentary: Is “as Good” Good Enough? James I. Fann. Semin Thoracic Surg 2017: 477-478.

ORIGINAL SUBMISSION: Aortic Valve Replacement Using a Perceval Sutureless Aortic Bioprosthesis. David Heimansohn. Oper Tech Thorac Cardiovasc 2016: 282-305.

ORIGINAL SUBMISSION: Intuity Elite Valve Implantation Technique. Kyle W. Eudailey. Oper Tech Thorac Cardiovasc 2016: 306-321. 


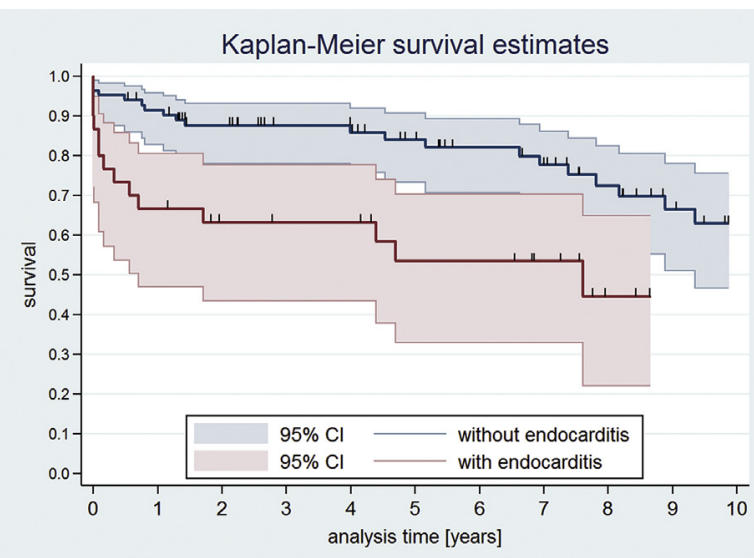

FIGURE E1. Actuarial survival (Kaplan-Meier) after reoperative aortic root replacement in patients with and without endocarditis. $C I$, Confidence interval.

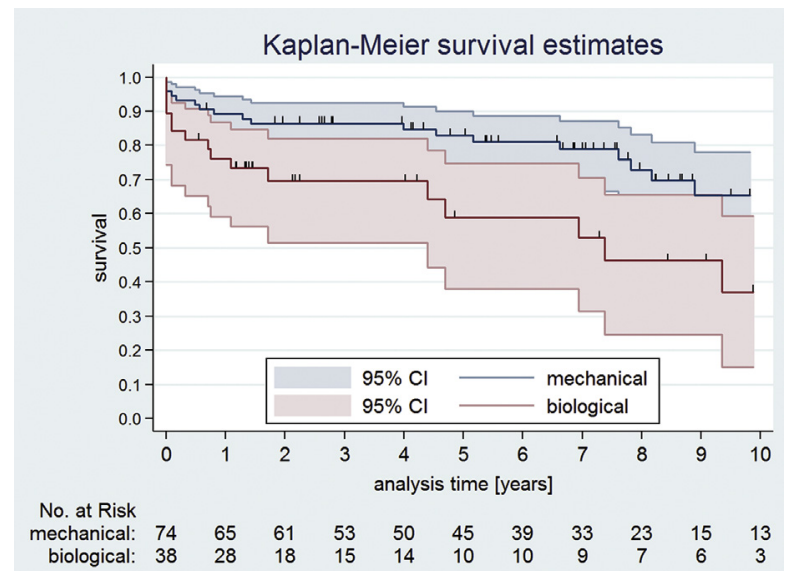

FIGURE E2. Actuarial survival (Kaplan-Meier) after reoperative aortic root replacement with mechanical and biological valve prostheses. CI, Confidence interval. 

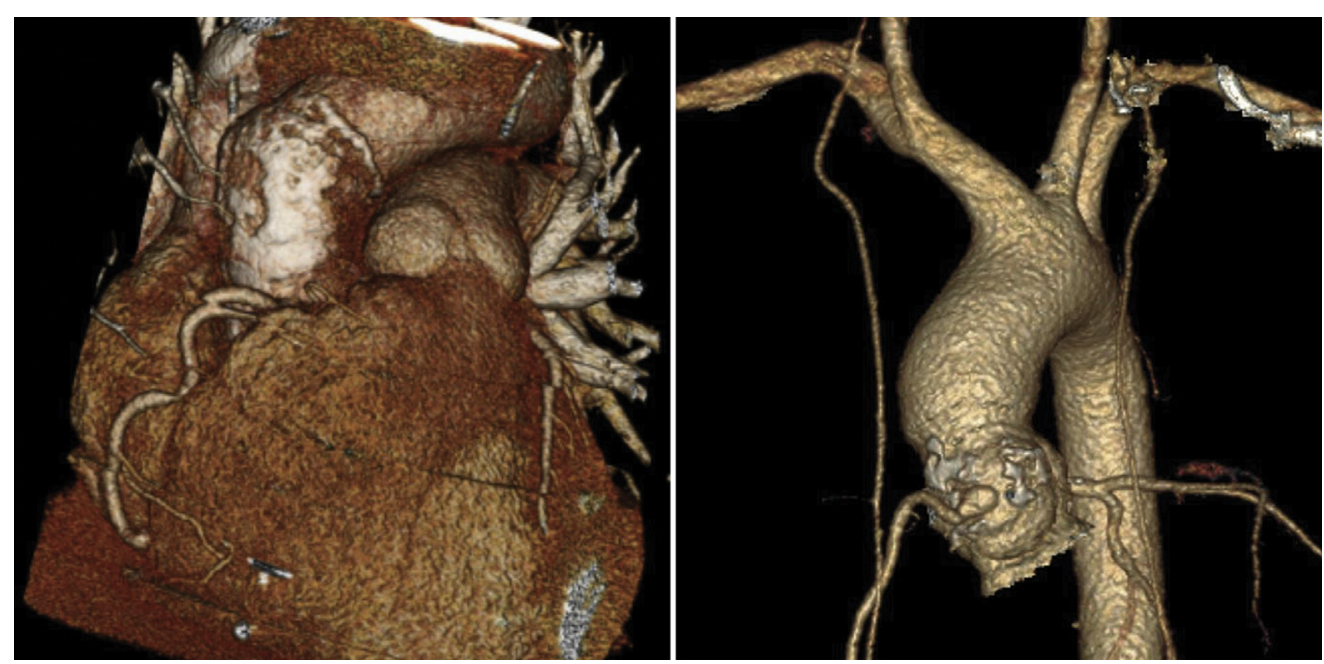

FIGURE E3. Extensive calcification of an aortic wall after root replacement with homograft (left) and xenograft (right). 